\title{
LA LIBERALIZACIÓN DEL SECTOR FERROVIARIO: ¿UNA POLÍTICA CONGRUENTE CON EL DERECHO COMUNITARIO DE LA COMPETENCIA?
}

\author{
MIREN IGONE ALTZELAI ULIONDO ${ }^{1}$ \\ igone.altzelai@ehu.eus
}

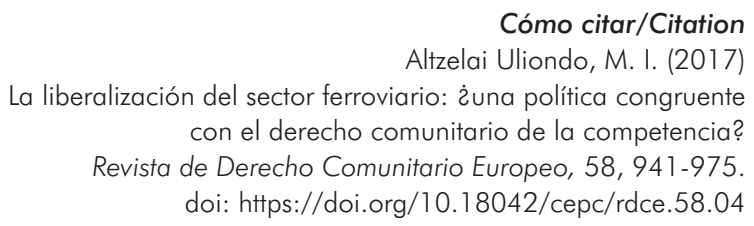

Resumen

El cuarto paquete ferroviario aprobado en 2016 con el fin de eliminar los obstáculos que quedan para completar el espacio ferroviario único europeo tiene por objeto, entre otros, impulsar la competencia adaptando para ello el sistema de gobernanza entre los gestores de las infraestructuras ferroviarias y los operadores de servicios. Sin embargo, a este respecto, la realidad nos muestra un panorama alejado de esos objetivos y dominado por unos pocos operadores. Este trabajo tiene por objeto analizar las causas de esa situación y proponer vías de mejora. Para ello se centra en un aspecto clave del proceso de liberalización del sector, como es el ámbito de las relaciones de mercado entre los administradores de infraestructuras ferroviarias y los operadores de los servicios de transporte, cuyo estudio se aborda desde la perspectiva del derecho comunitario de defensa de la competencia, con especial referencia al control de las concentraciones económicas.

1 Profesora contratada doctora de Derecho Mercantil de la Universidad del País Vasco/ Euskal Herriko Unibertsitatea (UPV/EHU). El presente trabajo ha sido elaborado gracias al proyecto de investigación «Derechos Fundamentales y Unión Europea», financiado por el Gobierno Vasco, en el marco de la Unidad de Formación e Investigación de la UPV/EHU «Integración política y económica en la Unión Europea». 


\title{
Palabras clave
}

Transporte ferroviario, liberalización, derecho comunitario, derecho de la competencia, control de concentraciones

\section{THE SINGLE EUROPEAN RAIL SPACE, A CONSISTENT POLICY WITH THE COMMUNITY LAW OF COMPETITION?}

\begin{abstract}
The Forth Railway Package approved in 2016 in order to remove remaining obstacles to complete the Single European Rail Area aims, inter alia, to boost competition by adapting the system of governance between railway infrastructure managers and service operators. However, in this respect, reality shows us a scenario away from those objectives and dominated by a few operators. This paper aims to analyze the causes of this situation and to propose ways of improvement. To this end, it focuses on a key aspect of the liberalization process of the sector, such as the area of market relations between railway infrastructure managers and transport service operators. The study is approached from the perspective of EC Competition law, with particular reference to rules applicable to merger control.
\end{abstract}

\section{Keywords}

Railway transport, liberalization, EC Law, Competition law, merger control

\section{L'ESPACE FERROVIAIRE UNIQUE ÚROPÉENNE, UNE POLITIQUE COMPATIBLE AVEC LE DROIT COMMUNAUTAIRE DE LA CONCURRENCE?}

\section{Résumé}

Le quatrième paquet ferroviaire adopté en 2016 afin d'éliminer les obstacles à compléter l'Espace Ferroviaire Unique Européen vise, entre autres, stimuler la concurrence pour adapter ce système de gouvernance entre les gestionnaires d'infrastructures et opérateurs de services ferroviaires. Cependant, à cet égard, la réalité nous montre un panorama loin de ces objectifs et dominé par quelques opérateurs. Ce document vise à analyser les causes de cette situation et de proposer des voies d'amélioration. Car il met l'accent sur un aspect clé du processus de libéralisation du secteur, comme le cadre des relations commerciales entre les gestionnaires d'infrastructures ferroviaires et les exploitants de services de transport. L'étude est abordée 
sous l'angle du droit communautaire de la concurrence, en particulier au contrôle des concentrations économiques.

\section{Mots clés}

Transport ferroviaire, libéralisation, droit communautaire, droit de la concurrence, contrôle des concentrations économiques 


\section{SUMARIO}

I. ALGUNAS CUESTIONES SOBRE LA LIBERALIZACIÓN DEL SETOR FERROVIARIO, ESPECIAL REFERENCIA AL TRANSPORTE DE PASAJEROS. II. RELACIONES DE MERCADO PELIGROSAS. III. MODELOS DE ESTRUCTURAS PARA LA GESTIÓN DE LAS INFRAESTRUCTURAS FERROVIARIAS Y LOS SERVICIOS DE TRANSPORTE: 1. EI modelo de integración vertical, monopolio natural. 2. Hacia un modelo dual. 3. Otros modelos de integración vertical, el modelo Holding. 4. Separación económica y separación institucional. IV. żINCONGRUENCIAS CON LAS NORMAS COMUNITARIAS DE LA COMPETENCIA?: 1. El control de las estructuras de mercado. 2. Criterios jurídicos vs. criterios económicos. 3. Valoración y perspectivas de futuro. V. CONCLUSIONES.

\section{ALGUNAS CUESTIONES SOBRE LA LIBERALIZACIÓN DEL SECTOR FERROVIARIO, ESPECIAL REFERENCIA AL TRANSPORTE DE PASAJEROS}

En el largo camino de la construcción de un espacio ferroviario único europeo, iniciado en la década de $1990^{2}$, la aprobación en 2016 del denominado cuarto paquete ferroviario constituye un último hito que tiene por objeto eliminar los obstáculos que quedan para completarlo. Realiza una revisión integral de la legislación en materia ferroviaria con el objetivo de darle el impulso definitivo, en torno a dos grupos de normas. El grupo conocido como pilar técnico ${ }^{3}$ abarca normas relativas a la seguridad, la interoperabi-

2 El proceso de liberalización del sector ferroviario en la Unión Europea se inicia formalmente con la Directiva 1991/440/CEE, del Consejo, de 29 de julio, sobre desarrollo de los ferrocarriles comunitarios (DO L 237 de 24 de agosto de 1991, pp. 2528). Véase asimismo, el Libro Blanco de la Comisión Europea, «Una estrategia para la revitalización de los ferrocarriles comunitarios», COM(1996) 421 final, 30.7.1996.

3 De acuerdo con la terminología empleada por la Comisión Europea y el Parlamento Europeo en la elaboración de las propuestas legislativas que conforman el cuarto paquete ferroviario, el denominado pilar técnico lo componen: i) la Directiva (UE) 2016/798, del Parlamento Europeo y del Consejo, de 11 de mayo de 2016, sobre la seguridad ferroviaria; ii) la Directiva (UE) 2016/797, del Parlamento Europeo y del 
lidad y la Agencia Ferroviaria de la Unión Europea. El grupo del pilar de mercado (también denominado pilar político o pilar de gobernanza) 4 contiene medidas sobre la gobernanza de los administradores de infraestructuras ferroviarias y los operadores de los servicios de transporte y sobre la liberalización del transporte interior de pasajeros al cual nos vamos a referir en este trabajo.

A lo largo de todos esos años han sido numerosos los esfuerzos realizados con el objetivo de crear un espacio ferroviario integrado y eficiente. Entre ellos destacan los relativos a la separación entre los administradores de infraestructuras ferroviarias y los operadores de transporte, la liberalización del transporte ferroviario de mercancías desde 2007 y del transporte internacional de viajeros desde 2010 y el establecimiento de organismos reguladores independientes y de servicios ferroviarios de interés general conocidos como obligaciones de servicio público 5 .

Pero, pese a ello, en 2013 la Comisión Europea puso de manifiesto 6 que aún había obstáculos importantes que dificultaban el desarrollo del sector

Consejo, de 11 de mayo de 2016, sobre la interoperabilidad del sistema ferroviario dentro de la Unión Europea, y iii) el Reglamento (UE) 2016/796 del Parlamento Europeo y del Consejo, de 14 de diciembre de 2016, relativo a la Agencia Ferroviaria de la Unión Europea y por el que se deroga el Reglamento (CE) 881/2004 (todos ellos en DO L 138, de 26 de mayo de 2016, pp. 1-149).

4 El pilar de mercado está integrado por: i) la Directiva (UE) 2016/2370, del Parlamento Europeo y del Consejo, de 14 de diciembre de 2016, que modifica la Directiva 2012/34/UE, en lo que atañe a la apertura del mercado de los servicios nacionales de transporte de viajeros por ferrocarril y a la gobernanza de las infraestructuras ferroviarias, y ii) el Reglamento (UE) 2016/2338 del Parlamento Europeo y del Consejo, de 14 de diciembre de 2016, que modifica el Reglamento (CE) 1370/2007, en lo que atañe a la apertura del mercado de los servicios nacionales de transporte de viajeros por ferrocarril (ambos publicados en el DO L 352, de 23 de diciembre de 2016, pp. $1-31)$.

5 Sobre la temática, en general, véase Luciano PAREJO ALFONSO, «Servicios públicos y servicios de interés general: la renovada actualidad de los primeros», Revista de Derecho de la Unión Europea, núm. 7 (2), 2004, pp. 51-68. Sobre el sector ferroviario, en particular: Juan José MONTERO PASCUAL, «La obligación de transporte público en el transporte ferroviario", Revista de Derecho de la Unión Europea, núm 25, 2013, pp. 127-150. Para un enfoque global de los servicios públicos en la Unión Europea, véase Wolf SAUTER, Public Services in EU Law, Cambridge University Press, 2014.

6 Comunicación de la Comisión al Parlamento Europeo, al Consejo, al Comité Económico y Social Europeo y al Comité de las Regiones relativa al cuarto paquete ferroviario: Completa el espacio ferroviario europeo único para fomentar la competitividad y el crecimiento europeos», $\operatorname{COM}(2013) 25$ final, 30.1.2013. 
ferroviario. Señaló la heterogeneidad de las diferentes formas de gobernanza del sector o la falta de coherencia en la aplicación de la legislación en el territorio de la Unión ${ }^{7}$, la existencia de prácticas contrarias a la competencia por parte de los operadores históricos y los administradores de infraestructuras y la falta de competencia en los mercados ferroviarios de transporte tanto de pasajeros como de mercancías ${ }^{8}$. Para mejorar esta situación, la Comisión presentó una propuesta de medidas que conforman el cuarto paquete ferroviario, aprobado en 2016, sobre cuyo pilar de mercado, sobre las cuestiones vinculadas a la gobernanza de los gestores de infraestructuras ferroviarias y operadores de servicios y la competencia en el transporte ferroviario, versa el presente trabajo.

Por una parte, con el objetivo de aumentar la competencia, para lograr mejores servicios ferroviarios más asequibles y rentables, la Directiva (UE) 2016/2370 prevé la apertura de los mercados de transporte de viajeros a partir del 1 de enero de 2019 y un escenario de concurrencia competitiva a partir de 24 de diciembre de 2023, a través de la realización de licitaciones públicas como modelo standard en la adjudicación de contratos de servicio público.

Por otra parte, para mejorar el sistema de apertura a la competencia o de liberalización efectiva, la directiva persigue prevenir los conflictos de intereses entre los administradores de las infraestructuras y los operadores de los servicios ferroviarios. Para ello incorpora un nuevo concepto jurídico de empresa integrada verticalmente e impone una serie de condiciones de transparencia financiera, especialmente con el fin de evitar las subvenciones cruzadas que tienen un efecto distorsionador sobre la competencia en el mercado. También prevé un acceso no discriminatorio a las redes ferroviarias y el material rodante para garantizar la igualdad de condiciones de todos los operadores.

Con todo ello, se prevé que la liberalización del sector genere oportunidades para las empresas ferroviarias y para los viajeros. Se espera que la existencia de empresas con capacidad para prestar servicios en este ámbito favorezca su racionalización y flexibilización y redunde en una mayor eficacia en la asignación de los recursos. También se espera que los usuarios del transporte

7 Véase a este respecto la Sentencia del Tribunal de Justicia Comisión/Alemania, C-482/14, EU:C:2017:499, sobre el recurso por incumplimiento interpuesto por la Comisión Europea, parte demandante, contra la República Federal de Alemania, parte demandada, apoyada por la República Italiana y la República de Letonia, partes coadyuvantes.

8 Miren Igone ALTZELAI ULIONDO, «El cuarto paquete ferroviario: luces y sombras», en María Victoria PETIT LAVALL y Achim PUETZ (dirs.), La eficacia del transporte como objetivo de la actuación de los poderes públicos: liberalización y responsabilidad, Marcial Pons, Madrid, 2015, pp. 673-691. 
ferroviario se vean beneficiados, que dispongan de más alternativas comerciales entre las que poder elegir.

Sin embargo, al lado de este panorama institucional que define el «deber ser» del espacio ferroviario único europeo observamos el «ser», una realidad económica muy diversa y alejada de esos objetivos. Puede incluso hablarse de una desordenada apertura del mercado europeo en el que cada país ha tomado una velocidad distinta. En la mayoría, los monopolios públicos dominan el transporte de pasajeros de larga distancia y la competencia, cuando la hay, se limita al ámbito del transporte regional. En el conjunto de la Unión, la realidad actual nos muestra dos operadores ferroviarios especialmente potentes, la empresa alemana DB (Deutsche Bahn) y la francesa SNCF (Société Nationale des Chemins de fer Français). Además de dominar sus mercados nacionales, en los últimos años se han extendido a otros países, de forma que han aumentado considerablemente su volumen de tráfico, llegando a duplicar su inversión en activos en algunas redes y, por ende, a ocupar posiciones de dominio también en el mercado europeo?.

El objeto del presente trabajo consiste en analizar las causas de esta situación y las actuaciones y decisiones de las instituciones comunitarias que han conducido a este resultado. Avanzamos que nuestra postura es crítica al respecto, por lo que planteamos una denuncia sobre la base de unos argumentos no meramente valorativos ni de carácter político, sino de unos parámetros jurídicos que pretenden poner de manifiesto las oscilaciones en el seno de la Unión Europea y sus efectos negativos. Asimismo, se propone la posibilidad de emplear otros cauces diferentes desde un enfoque novedoso (y creemos que necesario) como es el del derecho comunitario de defensa de la competencia ${ }^{10}$.

La liberalización entendida como apertura a la competencia de un sector implica la aplicación de las normas que disciplinan la competencia en el mercado. De hecho, las normas de competencia se aplican al sector del

9 A un nivel inferior les sucede la empresa Ferrovie dello Stato-Società di trasporti e servizi per azioni, véase Valentina ALLOTTI, «La liberalización de los ferrocarriles en Italia: entre las directivas europeas y la legislación nacional», Revista Transporte y Territorio, núm. 10, 2014, pp. 120-129.

10 Para otro enfoque del tema, desde el derecho administrativo, véase Jorge AGUDO GONZÁLEZ, «El derecho de organización como clave programadora de la actuación administrativa", Revista Jurídica de la Universidad Autónoma de Madrid, núm 31, 2015, pp. 15-49, que analiza la relevancia de los aspectos organizativos en el sector ferroviario para lograr la independencia del administrador de infraestructuras y su separación de las empresas ferroviarias. 
transporte ${ }^{11}$. Esta parte del ordenamiento jurídico opera como fundamento del orden político-económico, de una economía de mercado. Su función consiste en garantizar la existencia de una competencia efectiva, no falseada, en el conjunto del mercado común y pretende asimismo garantizar la consecución de un mercado único ${ }^{12}$. Por consiguiente, constituye un instrumento de referencia básico y eficaz para resolver los problemas derivados de aquellas políticas o estrategias regulatorias orientadas a unos resultados concretos, como es el complejo escenario del espacio ferroviario único europeo. En este sentido, con nuestra reflexión desde el enfoque del derecho comunitario de defensa de la competencia queremos contribuir a proponer posibles mejoras de futuro.

Debe admitirse que el proceso de liberalización del sector ferroviario, que comenzó hace más de veinticinco años y que aún no se ha culminado, no es comparable a otros procesos de liberalización de sectores que también estuvieron en tiempos en manos de monopolios nacionales, como es el caso del transporte aéreo o las telecomunicaciones, cuya apertura fue relativamente rápida y exitosa, con beneficios evidentes para los usuarios. En el sector ferroviario hay un elemento diferenciador clave que es la infraestructura, lo cual complica considerablemente todo este proceso. Hay una relación especial entre el vehículo que realiza el servicio de transporte, la infraestructura y los servicios asociados a ella que es mucho más intensa que en las demás modalidades de transporte ${ }^{13}$. De ahí se derivan problemas técnicos evidentes para la realización de un mercado único europeo, dada la fragmentación de la propia infraestructura integrada por redes nacionales con diferentes sistemas de señalización, anchos de vía, distintas tensiones eléctricas, tipología de las estaciones, etc. Pero también existen otros problemas o ineficiencias inherentes al mercado a los que nos vamos a referir en este trabajo.

11 Véase el considerando n.36 del Reglamento (CE) 1/2003 del Consejo, de 16 de diciembre de 2002, relativo a la aplicación de las normas sobre competencia previstas en los artículos 81 y 82 del Tratado, (DO L 1, de 4 de enero de 2003). Sobre el transporte por carretera, véase Patricia LIÑÁN HERNÁNDEZ, «Un paso más en la liberalización del transporte. La aplicación de las normas de competencia al sector del transporte por carretera», en María Victoria PETIT LAVALL y Achim PUETZ (dirs.), La eficacia del transporte como objetivo de la actuación de los poderes públicos: liberalización y responsabilidad, Marcial Pons, Madrid, 2015, pp. 277-286.

12 Jesús ALFARO ÁGUILA-REAL, «Autorizar lo que no está prohibido: una crítica a la regulación de los acuerdos verticales", Gaceta Jurídica de la Unión Europea y de la Competencia, núm. 229, 2004, pp. 51-67.

13 Juan José MONTERO PASCUAL, «La transición a la competencia en el transporte ferroviario", Revista de Derecho de la Competencia y la Distribución, núm. 4, 2009, pp. 121-136. 


\section{RELACIONES DE MERCADO PELIGROSAS}

Desde el punto de vista operativo, las relaciones entre los intervinientes en el mercado pueden abarcar un ámbito horizontal o vertical o también un ámbito horizontal y vertical, como ocurre en el caso de los conglomerados ${ }^{14}$. Las relaciones horizontales son aquellas que se desarrollan entre operadores activos en un mismo mercado de referencia, entre competidores directos que ofrecen el mismo tipo de productos o servicios ${ }^{15}$. Las relaciones verticales, en cambio, son relaciones entre empresas situadas en una misma cadena de valor pero en diferentes segmentos de la producción y/o distribución de los productos o servicios ${ }^{16}$. De acuerdo con este esquema, la relación que nos ocupa entre los gestores de infraestructuras ferroviarias y las empresas de servicios de transporte constituye una relación vertical. En la cadena de valor, los gestores de las infraestructuras ferroviarias son suministradores o proveedores y las empresas que ofrecen servicios de transporte son sus clientes o compradores. No operan en el mismo mercado, no ofertan servicios sustitutivos entre sí, sino servicios complementarios entre sí. Unos proporcionan el insumo productivo (las infraestructuras ferroviarias) que otros necesitan para llevar a cabo su actividad económica (las operaciones de transporte).

Desde el punto de vista del funcionamiento del mercado, las relaciones horizontales son las que se consideran especialmente peligrosas porque

14 En el caso de los conglomerados, las empresas participantes no pertenecen al mismo mercado. Sus actividades pueden ser complementarias o tener una relación «cercana» entre ellas de forma que, por ejemplo, la caída en el bien producido por una de las empresas eleva la demanda del bien ofertado por otra interviniente. Pero también pueden dedicarse a actividades diversas que no tienen vinculación alguna. Los conglomerados constituyen supuestos de concentración de empresas, de integración económica, vinculaciones que implican una mayor intensidad que los meros acuerdos entre empresas, dado que en ellos se produce un cambio duradero en el control de las empresas en el sentido del art. 3 del Reglamento (CE) 139/2004 del Consejo, de 20 de enero de 2004, sobre el control de las concentraciones de empresas (DO L 24, de 29 de enero de 2004, pp. 1-22) (Reglamento comunitario de concentraciones).

15 Según la Comunicación de la Comisión Europea relativa a la definición de mercado de referencia a efectos de la normativa comunitaria en materia de competencia (DO C 372, de 9 de diciembre de 1997, pp. 5-13), el mercado de producto de referencia comprende la totalidad de los productos y servicios que los consumidores consideren intercambiables o sustituibles en razón de sus características, su precio o el uso que se prevea hacer de ellos.

16 Véase al respecto el apdo. n. 24 de la Comunicación de la Comisión Europea de Directrices relativas a las restricciones verticales (DO C 130, de 19 de mayo de 2010). 
suelen conllevar riesgos de colusión, con la consiguiente pérdida de bienestar para los consumidores. A veces generan efectos positivos, pueden servir para compartir riesgos, ahorrar costes, incrementar las inversiones, agrupar conocimientos técnicos, aumentar la calidad y variedad de los productos o impulsar la innovación ${ }^{17}$. Pero normalmente se llevan a cabo para obtener poder de mercado o encierran la posibilidad de restringir la competencia ${ }^{18}$. Por ello se suelen analizar sus efectos reales y potenciales para determinar si son unos efectos restrictivos de la competencia apreciables (control anti-trust), aunque como regla general se presume que su contenido es colusorio, contrario a la ley (arts. 101.1 y 101.2 TFUE), sin que sea necesaria decisión previa alguna, si la relación consiste en un acuerdo o comportamiento de mercado $^{19}$. Cuando la relación es más intensa y entraña una concentración, el procedimiento es otro. La operación queda sometida a autorización previa, en caso de superar unos determinados umbrales ${ }^{20}$ (control de concentraciones).

Las relaciones verticales no tienen esa consideración. Aunque pueden conllevar efectos restrictivos para la competencia, por lo general, suelen ser menos peligrosas ${ }^{21}$. No obstante, son también susceptibles de causar efectos negativos, por lo que están igualmente sometidas al correspondiente control, que varía en función de la intensidad de la vinculación entre los participantes, según se trate de acuerdos (control anti-trust) o de casos de integración

17 Son relaciones beneficiosas en el sentido del art. 101.3 TFUE, cuyos efectos económicos y sociales superan el perjuicio de la colusión. Véase la Comunicación de la Comisión, Directrices sobre la aplicabilidad del artículo 101 del TFUE a los acuerdos de cooperación horizontal (DO C 11, de 14 de enero de 2011, p. 1).

18 Jesús ALFARO ÁGUILA-REAL, «La prohibición de los acuerdos restrictivos de la competencia. Una concepción privatística del derecho antimonopolio», In Dret, núm. 253, 2004, disponible en http://www.indret.com/pdf/253_es.pdf (consultado por última vez el 2.11.2017), se muestra crítico con la distinción entre acuerdos restrictivos por su objeto y acuerdos restrictivos por sus efectos en la jurisprudencia del TJUE.

Véase el art. 1 del Reglamento (CE) No 1/2003 del Consejo, de 16 de diciembre de 2002 , relativo a la aplicación de las normas sobre competencia previstas en los artículos 81 y 82 del Tratado (en adelante, Reglamento (CE) 1/2003). Sobre este modelo de prohibición de los comportamientos colusorios véase Eduardo GALÁN CORONA, «Notas sobre el Reglamento (CE) No 1/2003 del Consejo, de 16 de diciembre de 2002, relativo a la aplicación de las normas sobre competencia previstas en los arts. 81 y 82 del Tratado", Revista de Derecho Comunitario Europeo, núm. 15, 2003, pp. 499525.

20 Véase el art. 4 del Reglamento comunitario de concentraciones.

21 Directrices relativas a las restricciones verticales, op. cit., nota 15, n. 98. 
vertical (control de concentraciones), como los que encontramos en el ámbito ferroviario (infra. III y IV). En este ámbito, los riesgos para la competencia no son tanto de carácter horizontal, de generar poder de mercado mediante la coordinación de la conducta de los competidores ${ }^{22}$, sino de carácter vertical, y estas fundamentalmente plantean problemas para la competencia cuando existe una competencia insuficiente en uno o más niveles del comercio, es decir, cuando intervienen empresas dominantes con poder de mercado a nivel de comprador o de proveedor o de ambos ${ }^{23}$.

A estos riesgos de la competencia se añaden otros riesgos específicos del sector ferroviario, otras ineficiencias o fallos de mercado entre los que destacan la discriminación de los operadores en el acceso al mercado ferroviario y las subvenciones cruzadas.

Por una parte, está el hecho de que los costes de esta actividad son en su mayoría fijos, con importantes costes hundidos o costes irrecuperables de entrada relativos a la infraestructura, al material rodante y al capital humano, principalmente ${ }^{24}$. Los costes hundidos constituyen uno de los fallos de mercado típicos en las industrias de red como esta ${ }^{25}$, y los operadores necesitan un cierto volumen de tráfico para poder recuperarlos. De ahí resulta la relevancia que adquieren las economías de escala, ya que los costes medios de producción de los servicios disminuyen considerablemente al aumentar la

22 No obstante, también hay acuerdos verticales entre competidores, como los de distribución, cuyos efectos sobre el mercado y sobre la competencia pueden ser similares a los de los acuerdos horizontales. En ese caso se evalúan según los principios aplicables a los acuerdos horizontales. Véase Directrices sobre los acuerdos de cooperación horizontal, op. cit., nota 16, n. 6, 12 y 21. Si los acuerdos verticales afectan a una concentración, se aplica el Reglamento comunitario de concentraciones.

23 Según las Directrices relativas a las restricciones verticales, op. cit., nota 15, n. 6, 23, 97 , este poder de mercado se concreta en detentar una cuota de mercado superior al $30 \%$.

24 Rodolfo Ramos melero, «La prestación de los servicios de interés público en la Ley del Sector Ferroviario: orientaciones para su futuro desarrollo normativo», en Fernando Martínez Sanz y María Victoria Petit Lavall (dirs.) Aspectos jurídicos y económicos del transporte. Hacia un transporte más seguro, sostenible y eficiente, Universitat Jaume I, Castelló de la Plana, 2007, vol. I, pp. 341-357.

William J. Baumol y Robert. D. Willig, «Fixed Costs, Sunk Costs, Entry Barriers, and Sustainability of Monopoly»", The Quarterly Journal of Economics, núm. 96, 1981, pp. 405-431 y para una perspectiva de Derecho comunitario: Phedon NicoLAIDES, «Effective competition in network industries: An Assessment of Commission Decision 2001/354 imposing a fine on Deutsche Post for abusing its dominant position in parcel delivery»", European Competition Law Review, núm. 22, 2001, p. 390. 
escala o las unidades, es decir, los servicios de transporte prestados. También adquieren especial relevancia las economías de densidad, el ahorro que se genera en los costes de distribución del servicio, por ejemplo, cuando aumenta el número de usuarios de una zona, es decir, la concentración geográfica de la demanda. En definitiva, en los servicios ferroviarios y especialmente en el caso del transporte de viajeros, la posibilidad de competencia depende del volumen y de la densidad de las líneas. Si no hay unas condiciones mínimas a este respecto, la competencia no es factible.

Como los costes fijos son comunes a un alto número de servicios y líneas y las economías de escala y de densidad requieren grandes volúmenes de tráfico, resulta habitual un fallo de mercado como es la existencia de subvenciones cruzadas, típicas del sector. En otros tiempos los Gobiernos veían acertado subvencionar unos servicios con cargo a otros por razones sociales. Sin embargo, desde el punto de vista del mercado y la competencia estas subvenciones son inadmisibles ${ }^{26}$. Las subvenciones deben ser directas y transparentes, destinadas a cumplir unos objetivos sociales específicos, de forma que no afecten a la competencia en los mercados. Para ello es fundamental combatir la opacidad que caracteriza a las subvenciones cruzadas y conseguir la transparencia en la contabilidad de los $\operatorname{costes}^{27}$.

26 Carole MACZKOVICS, Geert VAN CALSTER y Bob MARTENS, Study on the implementation of regulation (EC) no $1370 / 2007$ on public assenger transport services by rail and by road, DLA Piper, Bruselas, 2010. Realizan recomendaciones para la Comisión Europea sobre cómo combatir las subvenciones cruzadas. Asimismo, véase Tim Maxian RUSCHE y Silvia SCHMIDT, "The post-Almark Era Has Started: 15 Months of Application of Regulation (EC) no 1370/2007 to public transport services», European State Aid Law Quarterly, núm 10 (2), 2011, pp. 249-263.

27 Esa es, precisamente, la finalidad del anexo (apdo. n. 5) al Reglamento (CE) 1370/2007 del Parlamento Europeo y del Consejo, de 23 de octubre de 2007, sobre los transportes públicos de los viajeros por ferrocarril y carretera y por el que se derogan los Reglamentos (CEE) 1191/69 y (CEE) 1107/70 del Consejo, (DO L 315, de 3 de diciembre de 2007), al establecer una serie de condiciones mínimas de contabilidad para estos servicios.

En opinión de Loris DI PIETRANTONIO y Jacques PELKMANS, «The Economics of EU Railway Reform», Bruges European Economic Policy, núm. 8, College of Europe 2004, pp. 18, disponible en http://citeseerx.ist.psu.edu/viewdoc/download?doi=10.1.1.116.7420\&rep=rep1 \&type=pdf (consultado por última vez el 2.11.2017), incluso unas reglas contables estrictas para la separación de cuentas entre las principales líneas de negocio son quizá insuficientes para prevenirlo totalmente. 
Por otra parte, la posición de ventaja de las compañías históricamente establecidas, derivada de la dimensión alcanzada de las economías obtenidas a lo largo de muchos años, es un primer obstáculo a la entrada de participantes en el mercado. Pero además, el sector ferroviario se caracteriza por concitar especiales riesgos de discriminación en el acceso de los operadores al mercado, sobre todo, en el acceso a las infraestructuras, en las tarifas establecidas por su uso y en el acceso al material rodante.

Una de las condiciones necesarias para el funcionamiento de la competencia es el acceso no discriminatorio de los operadores a las infraestructuras, tanto a la red ferroviaria como a las demás instalaciones (estaciones, andenes, etc.) que son esenciales y presentan un carácter de monopolio natural (essential facilities $)^{28}$. La gestión de estas infraestructuras no está abierta a la competencia, pero se encomienda a una empresa distinta de los operadores servicios de transporte, a fin de asegurarles un acceso no discriminatorio a ellas. Es lo que ordena el primer paquete ferroviario ${ }^{29}$, aunque no elimina per se ese riesgo. No impide que de facto el gestor deniegue el acceso a la infraestructura o imponga un trato gravoso a determinados operadores de servicios, generando así problemas de abuso de su posición de dominio. Ese trato gravoso puede producirse en la adjudicación de capacidad disponible o adjudicación de surcos para los operadores, por ejemplo ${ }^{30}$. Por ello, sea cual sea el sistema de adjudicación que se adopte, es preciso garantizar la transparencia y unas condiciones no discriminatorias para todas las empresas ferroviarias ${ }^{31}$.

28 Sobre el tema véase in extenso la tesis doctoral de Eva MARTÍNEZ ALIFA, El Derecho del Transporte en la Unión Europea: la reforma estructural del sector ferroviario y la aplicación de la doctrina de los recursos esenciales, Universidad Complutense de Madrid, 2013, dirigida por Nicole STOFFEL VALLOTTON, disponible en http://eprints. ucm.es/22329/ (consultado por última vez el 2.11.2017).

29 Directiva 2001/14/CE, del Parlamento Europeo y del Consejo, de 26 de febrero de 2001, relativa a la adjudicación de la capacidad de infraestructura ferroviaria, aplicación de cánones por su utilización y certificación de la seguridad, (DO L 75 de 15.3.2001, pp. 29-46).

30 Ibid. art. 2.g), la capacidad de infraestructura es el potencial para programar las franjas ferroviarias solicitadas para un segmento de la infraestructura durante un determinado período de tiempo. Art. 3, toda la información necesaria para la utilización de los derechos de acceso debe ser publicada en una declaración de red. Las normas de referencia para los sistemas de adjudicación de capacidad de infraestructura están en el art. 13 ss.

31 Mihalis KEKELEKIS y Phedon NICOLAIDES, «Public Financing of Urban Transport: the application of EC State Aid Rules», World Competition, núm. 31 (3), 2008, pp. 421-448. 
Otro trato discriminatorio puede derivarse de las tarifas aplicadas por el administrador por el uso de las infraestructuras ${ }^{32}$. Los ingresos derivados de estas tarifas son esenciales para que el gestor de la infraestructura pueda cubrir los costes de la misma. Ese es su objetivo, por ello debe tratar de mantener una situación de equilibrio entre los ingresos (provenientes de los cánones por utilización, los excedentes de otras actividades comerciales y la financiación estatal) y los gastos de la infraestructura ${ }^{33}$.

Finalmente, está el acceso al material rodante y a las instalaciones técnicas para su mantenimiento, que es otra de las condiciones indispensable para la entrada de nuevos operadores. Las empresas ferroviarias pueden adquirir material rodante nuevo, de segunda mano o alquilarlo. Pero la primera opción solo es factible para unas pocas empresas que cuentan con una capacidad financiera fuerte. En la mayoría de los Estados el material rodante para pasajeros es de propiedad del operador histórico y la experiencia de alquiler se centra básicamente en el ámbito del transporte de mercancías, aunque empieza a abrirse al transporte de viajeros ${ }^{34}$. Así pues, este es un mercado muy reducido que requiere ser vigilado debido a sus imperfecciones: una oferta restringida y poco adaptada a la demanda, unos precios de alquiler elevados, pocos competidores, por tanto, peligro de abuso de posición dominante.

\section{MODELOS DE ESTRUCTURAS PARA LA GESTIÓN DE LAS INFRAESTRUCTURAS FERROVIARIAS Y LOS SERVICIOS DE TRANSPORTE}

En este contexto del sector ferroviario, en el que intervienen unas relaciones de mercado de carácter vertical entre los gestores de infraestructuras ferroviarias y los operadores de servicios de transporte, procederemos a analizar a continuación los diferentes niveles de intensidad de esas relaciones que se presentan bajo morfologías distintas y diversas modalidades de vinculación y a

32 Véase la Resolución del Comité de Regulación Ferroviaria en el Expediente CRF 2011/003, por reclamación de RENFE-Operadora contra ADIF por liquidación del canon por tráfico.

33 El Estado podría incluso exigir al administrador de la infraestructura que equilibrase sus cuentas sin financiación estatal. Véase el art. 6.1 de la Directiva 2001/14/CE.

$34 \mathrm{Al}$ respecto, véase el informe de Everis-Strategic Development \& Consulting, Study on Regulatory Options on Further Market Opening in Rail Passenger Transport, 2010, pp. 44 y ss., disponible en https://ec.europa.eu/transport/sites/transport/files/modes/rail/ studies/doc/2010_09_09_study_on_regulatory_options_on_further_market_opening_in_rail_passenger_transport.pdf (consultado por última vez el 2.11.2017). 
analizar las consecuencias que de ello se derivan para la creación de un espacio ferroviario único europeo en competencia.

\section{EL MODELO DE INTEGRACIÓN VERTICAL, MONOPOLIO NATURAL}

En Europa, el transporte por ferrocarril comenzó a desarrollarse a principios del siglo XIX, gracias a la iniciativa privada ${ }^{35}$. En esos tiempos el modelo organizativo integraba verticalmente la gestión de la infraestructura (incluida la construcción) y la explotación de los servicios de transporte. Se trataba de un modelo muy poco eficiente. Solo lo era en algunos casos y su expansión estaba supeditada a la rentabilidad de la demanda esperada ${ }^{36}$. Así, los pequeños operadores ferroviarios pioneros fueron desapareciendo a través de fusiones y absorciones. Surgieron nuevas empresas de ámbito regional o nacional con un elevado poder de mercado y con importantes vínculos industriales y comerciales. El sector ferroviario fue creciendo y adquiriendo importancia, no solo en términos económicos sino también políticos, hasta convertirse en un sector estratégico y de carácter público. La mayoría de los operadores acabaron siendo nacionalizados.

Por consiguiente, en el siglo $\mathrm{xx}$, el modelo dominante en casi todos los países fue el de un único operador ferroviario de carácter público estatal que integraba verticalmente tanto la gestión de las infraestructuras como la explotación de los servicios de transporte, en un contexto en el que la red ferroviaria constituía un monopolio natural. Esta era la regla general ${ }^{37}$, no solo en el sector ferroviario sino también en la mayoría de las llamadas industrias de red (transporte aéreo, telecomunicaciones, energía, etc.). De hecho, estaba extendida la creencia de que en estos sectores la competencia no era posible ni deseable ${ }^{38}$, debido a determinados rasgos específicos que presentan estas industrias, unas infraestructuras necesarias para el proceso productivo, tecno-

35 John HIBBS, «Railways and the power of emotion: from private to public ownership", en VV. AA., The Railways, the Market and the Government, Institute of Government Affairs, Londres, 2006, pp. 21-44.

36 Javier CAMPOS MÉNDEZ, «La competencia en el ferrocarril: un análisis del nuevo marco institucional en Europa y en España», FEDEA (Fundación de Estudios de Economía Aplicada) Policy Papers, núm. 12, 2015, p. 4.

37 Ibid,. p. 5, con alguna notable excepción como la de Estados Unidos y de que en algunos países se permitía la existencia de otros operadores, aunque generalmente de carácter local.

38 John D. BITZAN, «Railroad Costs and Competition: the Implicaions of Introducing to Railroad Networks", Journal of Transport Economics and Policy, núm. 37 (2), 2003, pp. 201-225. 
lógicamente complejas, con costes de construcción elevados. Esto hace que las economías de escala y de densidad resulten especialmente relevantes, lo cual da lugar a empresas de gran tamaño y a redes de amplia cobertura. Así pues, las ventajas de costes asociadas al tamaño generaron estructuras de mercado de carácter monopolístico (monopolios naturales).

Estos factores económicos confieren a las industrias de red unas características específicas. Son sectores que cuentan con un bajo número de competidores potenciales, por tanto propensos a posiciones de dominio, y con un alto grado de integración entre las infraestructuras y la producción de los servicios. Además, hay una tendencia generalizada a que las subvenciones públicas cubran los costes de las infraestructuras ${ }^{39}$, por lo que cuentan con un cierto grado de participación pública. En opinión de algunos, debido a estos rasgos, las industrias de red se alejan claramente de los modelos de competencia perfecta. En el caso del transporte por ferrocarril, estas características han servido tradicionalmente para defender el modelo de monopolio público verticalmente integrado, amparado en una concepción de monopolio natural y políticamente protegido. El hecho de que la propiedad de las infraestructuras y de los operadores ferroviarios haya sido pública y que cada Estado tuviese su propia normativa ha sido y sigue siendo uno de los principales obstáculos para la creación de un espacio ferroviario europeo único.

\section{HACIA UN MODELO DUAL}

En la década de 1980 y más en la de 1990 muchos países iniciaron procesos de reestructuración del sector ferroviario, con el objetivo de disminuir la presencia del sector público y comenzar a introducir la competencia, en gran medida movidos por el ánimo de buscar una mayor eficiencia económica de los operadores del sector que se encontraban en franca decadencia. A este respecto, las experiencias son numerosas, pero pueden identificarse tres modelos principales: i) la desintegración vertical o separación entre la administración de las infraestructuras y los servicios de transporte; ii) la privatización, mediante la enajenación de los activos de los antiguos monopolios públicos o mediante concesiones de larga duración para la explotación de los servicios y iii) la desregulación, principalmente en lo relativo a las tarifas y a las condi-

39 CAMPOS, op. cit., nota 36, p. 7, si a los precios que pagan los usuarios hubiera que imputar los costes de explotación e inversión de la infraestructura, la actividad no sería económicamente rentable sino prácticamente inviable. 
ciones de acceso al mercado ${ }^{40}$. En la mayoría de los casos, no hay un modelo puro, sino una combinación de variantes con preeminencia de uno de ellos ${ }^{41}$. De todos modos, coincidimos con quienes opinan que cuando un país, o la propia Unión Europea, pretende introducir la competencia en el sector ferroviario, las dos decisiones más controvertidas que debe tomar son: primero, si debe o no proceder a la desintegración vertical y, segundo, cómo debe gestionarse y regularse el sector a partir de ese momento ${ }^{42}$.

En la Unión Europea, el proceso de liberalización del sector ferroviario se inició sobre la premisa de la conveniencia de separar la administración de las infraestructuras y los servicios de transporte ${ }^{43}$, con el fin de garantizar el acceso a la red a los potenciales operadores. Pero la definición de esa separación ha acarreado y sigue acarreando numerosos problemas. En un contexto en el que la infraestructura ferroviaria constituía un monopolio natural, se decidió otorgar la administración de las redes nacionales a un único gestor, obligado a proporcionar el acceso a dichas infraestructuras a los operadores de transporte ferroviarios bajo unas condiciones objetivas, transparentes, no discriminatorias y sujetas a regulación. Simultáneamente, se introdujeron medidas dirigidas a integrar mercados nacionales y a introducir competencia entre los operadores de transporte ferroviario.

En una fase inicial, la Directiva 91/440/CE sobre el desarrollo de los ferrocarriles comunitarios obligó a los Estados miembros a adaptar sus marcos legales al objeto de cumplir dos obligaciones: la independencia de gestión y la separación contable entre la administración de la infraestructura y las

40 Miren Igone ALTZELAI ULIONDO, «¿Competencia «por» el mercado o competencia «en» el mercado de los servicios de transporte de viajeros por ferrocarril?», en Achim PUETZ (coord.) y M. Victoria PETIT, MARTÍNEZ y Andrés RECALDE (dirs.), La nueva ordenación del mercado de transporte, Marcial Pons, Madrid, 2013, pp. 85-105.

41 RAMOS MELERO, op. cit., nota 23, p. 423.

42 CAMPOS, op. cit., nota 36 p. 10.

43 En la Comunicación de la Comisión Europea al Consejo, 25 de enero de 1990, La política ferroviaria comunitaria, se esboza el diseño de un sistema ferroviario común basado en la separación entre la infraestructura y el transporte, a diferencia del modelo estadounidense de integración vertical en que el administrador de infraestructuras y el operador del servicio ferroviario pueden operar bajo la misma dirección comercial. Véase asimismo, el informe de la Comisión Nacional de La Competencia, «Trabajando por la competencia. Informe sobre la competencia en el transporte de mercancías por ferrocarril en España", Madrid, 2013, p. 13., accesible en: www.cncompetencia. es (consultado por última vez el 11.2.2017). 
operaciones de transporte ${ }^{44}$. Imponía a los Estados la obligación de adoptar las medidas necesarias para que, en materia de dirección, gestión, administración y control administrativo, económico y contable interno, las empresas ferroviarias estuvieran dotadas de un estatuto independiente con arreglo al cual dispusieran de patrimonio, presupuesto y contabilidad independientes de los de los Estados (art. 4, Directiva 91/440/CE). Asimismo, obligaba a los Estados miembros a adoptar medidas para garantizar la separación contable entre las actividades relativas a la administración de la infraestructura y a las operaciones de transporte. Además, prohibía que las ayudas que se concediesen a una de estas actividades pudieran transferirse a la otra (art. 6, Directiva 91/440/ $\mathrm{CE}$ ). Exigía que la contabilidad de las dos actividades se llevara de modo que pudiera verificarse el incumplimiento de dicha prohibición; en definitiva, que las cuentas y los balances publicaran por separado las actividades de explotación de los servicios de transporte y de administración de la infraestructura ferroviaria. La financiación pública también debía reflejar esta separación.

La directiva contemplaba la posibilidad de que esta separación contable obligatoria se combinara con una separación orgánica o con una separación institucional (art. 7, Directiva 91/440/CE). Daba libertad a los Estados para ordenar la exigencia de divisiones orgánicas diferenciadas — para las infraestructuras y para los transportes - en el seno de una misma empresa o persona jurídica (separación orgánica) o para ordenar que las actividades de gestión de infraestructuras y de servicios de transporte fueran a cargo de entidades jurídicas distintas (separación institucional). Sin embargo, muchos países tardaron en incorporar plenamente esta directiva.

El primer paquete ferroviario $(2001)^{45}$, que perseguía profundizar en la separación contable entre los gestores de las infraestructuras y los operadores de transporte, mantuvo como regla general la voluntaria separación orgánica o separación institucional de ambas actividades, con una salvedad. Impuso que las funciones de los administradores de infraestructuras calificadas de esenciales — la asignación de surcos y la tarificación— estuvieran separadas de las

44 Directiva 91/440/CE del Consejo, de 29 de julio de 1991, sobre el desarrollo de los ferrocarriles comunitarios (DO L 237 de 24.8.1991, pp. 25-28). Excluye de su ámbito de aplicación a los operadores privados de vagones de mercancías y a las empresas de ámbito suburbano, urbano o regional.

45 Directiva 2001/12/CE del Parlamento Europeo y del Consejo, de 26 de febrero de 2001, por la que se modifica la Directiva 91/440/CE sobre el desarrollo de los ferrocarriles comunitarios (DO L 75, de 15 de marzo de 2001, pp. 1-25). 
operaciones de transporte. Pero la incorporación de las medidas del primer paquete no fue homogénea en el conjunto de la Unión ${ }^{46}$.

El segundo paquete ferroviario (2004) y el tercero (2007) incidieron en otros aspectos distintos a la separación entre las actividades de gestión de las infraestructuras y de prestación de los servicios de transporte ${ }^{47}$. En cambio, pese a no estar incluida en ningún paquete ferroviario, fue clave la Directiva 2012/34/UE ${ }^{48}$ de refundición del primer paquete y de establecimiento de un espacio ferroviario europeo único. Reforzó la independencia de las empresas ferroviarias y los administradores de infraestructuras respecto de los Estados (art. 4). Avanzó en la separación que debe existir respecto de los gestores de infraestructuras cuando las actividades de infraestructuras y de transportes se desarrollen por la misma empresa (arts. 6 y 7), exigiendo, al menos, una separación orgánica y dejando a los Estados miembros la opción de exigir una separación institucional, que cada una de las actividades fuera a cargo de entidades jurídicas distintas. Asimismo, el art. 7 estableció la independencia que debe tener el administrador de infraestructuras cuando desarrolle sus funciones esenciales de asignación de surcos y de tarificación.

Con todo, el modelo así definido no ha resultado eficaz y ha estado rodeado de problemas en su aplicación ${ }^{49}$. Hay Estados que discuten el significado preciso de las normas de la Unión Europea y las aplican según su interpretación o no las aplican plenamente. En puridad, las normas imponen las siguientes exigencias: i) la independencia respecto del Estado de la gestión de las empresas de transporte ferroviario y de los administradores de infraestructuras; ii) la separación contable entre la administración de las infraestructuras

46 Bélgica, Dinamarca, España, Francia, Italia, Países Bajos y Portugal notificaron su implantación total, mientras que Alemania, Austria, Grecia, Reino Unido y Suecia no notificaron ningún avance, por lo que la Comisión Europea inició recurso contra ellos por incumplimiento de los plazos ante el TJUE. Sobre la legislación europea y experiencias de la época, véase Luciano PAREJO ALFONSO, Manuel GÓMEZ MEJÍAS, Antonio FUERTES MARTÍN y Daniel ENTRENA RUIZ, Estudio sobre la ordenación del sector ferroviario en la Unión Europea (El marco comunitario y los casos alemán, francés, británico y español), Marcial Pons, Madrid, 2004.

47 Destinados a desarrollar un enfoque común de seguridad, la interoperabilidad, la liberalización del transporte de mercancías por ferrocarril y la creación de una Agencia Ferroviaria Europea, entre otros.

48 Directiva 2012/34/UE del Parlamento Europeo y del Consejo, de 21 de noviembre de 2012, por la que se establece un espacio ferroviario europeo único (DO L 343, de 14 de diciembre de 2012, pp. 32-77).

49 Memorándum de la Comisión Europea, "Los retos futuros del ferrocarril europeo», MEMO/13/45, 30.1.2013, p. 3. 
y las operaciones de transporte (separación de las cuentas de pérdidas y ganancias, de los balances y de las ayudas públicas), y iii) la separación institucional de las funciones esenciales del administrador de infraestructuras — la asignación de surcos y la tarificación - respecto de los operadores de transporte. No se exige la separación de las demás funciones del administrador de infraestructuras, como son las decisiones sobre mantenimiento, la gestión diaria del tráfico ferroviario, las decisiones sobre el desarrollo de la infraestructura, etc. Todas estas funciones pueden ser realizadas por una entidad vinculada a una empresa de transporte ferroviario que, en la práctica, sigue siendo la empresa histórica nacional.

Con este marco jurídico, más o menos la mitad de los Estados miembros que cuentan con un sistema de transporte ferroviario han ido más allá de estos mínimos exigidos por la legislación de la Unión Europea ${ }^{50}$. Han optado por el modelo dual, de separación institucional entre un gestor de infraestructuras con plenas funciones y los operadores de transporte. Sin embargo, otros se han ceñido a esos mínimos entendidos de forma restrictiva, por tanto, a una separación limitada, circunscrita únicamente a las funciones esenciales de los administradores de infraestructuras. Respecto a estos casos, debe decirse que las empresas históricas de algunos países han aprovechado esta posibilidad legal y estas circunstancias, por un lado, para discriminar a los nuevos operadores y obstaculizarles el acceso a sus mercados nacionales y, por otro, gracias al poder económico de su estructura integrada, para extender su actividad a otros países que han adoptado un modelo dual de desintegración vertical del operador histórico.

\section{OTROS MODELOS DE INTEGRACIÓN VERTICAL, EL MODELO HOLDING}

Frente a un modelo dual, de separación institucional entre el administrador de infraestructuras y los operadores de servicios de transporte, hay Estados que han preferido estructuras más sofisticadas de integración vertical, ya sea una estructura plenamente integrada delegando las funciones esenciales de los gestores de infraestructuras a organismos externos o una estructura de holding donde la entidad encargada de gestionar la infraestructura es una

50 CAMPOS, op. cit., nota 36, p. 20. Han optado por la desintegración vertical: Bulgaria, Chequia, Croacia, Dinamarca, Eslovaquia, España, Finlandia, Grecia, Holanda, Portugal, Reino Unido, Rumania y Suecia. Cuentan con una estructura de integración vertical: Alemania, Austria, Bélgica, Croacia, Eslovenia, Estonia, Francia (antes con desintegración), Hungría, Irlanda, Italia, Letonia, Lituania, Luxemburgo y Polonia. 
de las entidades jurídicas que lo conforman, como es el caso emblemático de Alemania $^{51}$, entre otros ${ }^{52}$.

Este modelo de integración vertical ha sido cuestionado en ocasiones por la propia Comisión Europea — también por autoridades nacionales ${ }^{53}$ por considerar que estas estructuras carecen de independencia entre el administrador de infraestructuras y el operador de los servicios de transporte. Pero los recursos interpuestos por la Comisión han sido rechazados por el TJUE por estimar que la existencia de esa falta de independencia no ha sido suficientemente probada ${ }^{54}$. El TJUE no dice expresamente que la estructura de holding sea compatible con la normativa comunitaria, sino que no se ha probado la falta de independencia exigida por las directivas comunitarias ${ }^{55}$. Este hecho ha traído importantes consecuencias. Así, Francia, un país con operadores ferroviarios importantes, ha procedido a acometer la reintegración vertical del gestor de infraestructuras y los operadores de transportes que antes había separado ${ }^{56}$. Otros países, como es el caso de España, con operadores de

51 Comisión Nacional de La Competencia, op. cit., nota 43, p. 161. Su estructura interna en un primer momento abarcaba cuatro divisiones: transporte local y regional de pasajeros (DB Regio), transporte de viajeros de larga distancia (DB Bahn), estaciones y servicios (DB Station \& Service) e infraestructuras (DB Netz), pero actualmente cuenta con diez divisiones principales, además de otras líneas de negocio (consultoría de ingeniería, negocios inmobiliarios, etc. Información disponible en www.deutschebahn.com/de/konzern/Konzernunternehmen/11877764/Beteiligungen (consultado por última vez el 31.7.2017). En 2008 se produjo una reestructuración interna y se preveía la salida a bolsa de una parte del capital de la compañía, pero el Estado sigue manteniendo la totalidad de las acciones.

52 Sobre el caso italiano véase ALLOTTI, op. cit., nota 8, pp. 120-129.

53 Monopolkommission, «Bahn 2015: Wettbewerbspolitik aus der spur?»», Sondergutachten 69, 2015, accesible en: www.monopolkommission.de/index.php/de/gutachten/sondergutachten/sondergutachten-69 (consultado por última vez el 2.11.2017).

54 Véanse las sentencias del Tribunal de Justicia Comisión/Alemania, C-556/10, EU:C:2013:116 y C-482/14, EU:C:2017:499.

55 Véase el documento del Pleno de la Comisión Nacional de los Mercados y la Competencia, Documento de reflexión sobre el proceso de liberalización del transporte de viajeros por ferrocarril, PRO/DTSP/0001/14, Madrid, 25 de junio de 2014, pp. 14.

56 En la década de 1990 procedió a separar las actividades ferroviarias. En 1997 se creó Résseau Ferré de France (RFF) para la administración y mantenimiento de las infraestructuras, y la que era monopolio público Société Nationale de Chemins de Fer Français (SNCF) pasó a tener una estructura con cinco unidades de negocio: mantenimiento y explotación de infraestructura (SNF Infra), transporte público urbano, metropolitano y regional (SNF Proximité), transporte de pasajeros de larga distancia y alta velocidad (SNF Voyages), transporte y logística de mercancías (SNF Geodis) y 
infraestructuras y de transportes separados, también contemplan la idea de su reintegración vertical mediante una estructura de holding.

En los últimos años asistimos a una fuerte corriente crítica hacia estos modelos de integración por considerar que generan problemas de ineficiencia en la gestión de las infraestructuras, de uso de los fondos públicos, de competencia y de mercado ${ }^{57}$. Respecto a estos últimos, se señalan como típicas las distorsiones sobre la competencia del gestor de infraestructuras por aplicar unas tarifas notablemente más reducidas a las empresas de su holding que a sus competidores $^{58}$, por incrementar considerablemente las tarifas de acceso a las vías a los nuevos operadores ${ }^{59}$ o por desarrollar estrategias para dejar fuera del mercado a un operador ${ }^{60}$.

A estos problemas hay que añadir las asimetrías de información que hacen que los operadores históricos tengan ventajas competitivas así como el riesgo persistente de subvenciones cruzadas ${ }^{61}$, con desvíos de fondos asignados al desarrollo de la infraestructura utilizados para proporcionar una ventaja competitiva a las actividades de transporte del operador histórico. Con los gestores de red integrados en grandes compañías nacionales, es difícil asegurar que se cumple la separación de flujos financieros dentro de un grupo integrado, por lo que es muy posible que las aportaciones públicas o los ingresos de

gestión y desarrollo de las estaciones (SNF Gares et Connexions). No obstante, Francia presentaba la particularidad de que RFF estaba obligada por ley a subcontratar a SNCF las operaciones de gestión y mantenimiento de la infraestructura y SNCF llevaba a cabo la gestión conforme a los criterios definidos por RFF. Este sistema tan peculiar hacía que la separación entre RFF y SNCF fuera más formal que real, ya que otorgaba un papel preponderante a SNCF y dejaba a RFF como un operador casi sin funciones.

57 Memorándum de la Comisión Europea, op. cit., nota 49, p. 4.

La autoridad alemana de la competencia descubrió que el sistema de tarificación TPS 1998 permitía a DB Regio fijar unas tarifas entre un $25 \%$ y un 40 \% más reducidas que a sus competidores.

59 La empresa histórica austríaca ÖBB Infrastruktur incrementó considerablemente las tarifas de acceso a las vías para los servicios de pasajeros después de que una empresa de nueva incorporación al mercado, West Bahn, anunciara el comienzo de sus operaciones competidoras en la línea Viena-Salzburgo.

60 La autoridad italiana de la competencia, a raíz de una denuncia, sancionó al grupo Ferrovie dello Satato y le impuso una multa de 300.000 euros al descubrir que a través de sus subsidiarias RFI y Trenitalia había puesto a punto una estrategia compleja y unificada para dejar a competidora Arenaways (en concurso de acreedores en el momento de la decisión) fuera de la lucrativa ruta Milán-Turín entre 2008 y 2011.

61 Memorándum de la Comisión Europea, op. cit., nota 49, p. 5. 
los cánones de acceso a la infraestructura acaben funcionando como subvenciones cruzadas entre los operadores del holding. Para evitarlo debería haber una independencia jurídica y económica — comercial y financiera - entre ambas instancias ${ }^{62}$, algo que no se garantiza con las normas previstas para la liberalización del sector ferroviario hasta el momento.

Por su parte, las grandes compañías como DB y SNCF cuentan con estudios en defensa de la integración vertical que muestran que una estructura integrada no es sinónimo de ausencia de competencia y de monopolio público ineficiente ${ }^{63}$. Sin embargo, debe recordarse que ambas empresas se han beneficiado ampliamente en los últimos años de aquellos mercados en los que el operador vertical se ha dividido o desaparecido. Así, por ejemplo España, tras separar la gestión de la infraestructura y los servicios de transporte, ha visto cómo DB y SNCF han penetrado sin problemas en sus mer$\operatorname{cados}^{64}$. En el Reino Unido, en el transporte de viajeros, DB cuenta con una alta implantación a través de su filial Arriva ${ }^{65}$. Por su parte, SNCF opera en Estados Unidos principalmente en el ámbito de cercanías a través de su filial Keolis (Keolis North America) ${ }^{66}$ prestando servicios para Virginia Railway Express $^{67}$ y para Massachusetts Bay Transportation Authoritie ${ }^{68}$. Asimismo,

62 Sim KALLAS, comisario de transportes, en el comunicado de prensa de la Comisión Europea «Los ferrocarriles europeos en la encrucijada: la Comisión adopta propuestas para un cuarto paquete ferroviario», Bruselas, 30 de enero de 2013.

DB y SNCF presentaron un informe solicitado y financiado por ellas en rueda de prensa conjunta el 15 de octubre de 2012. Véase la noticia en la publicación Alta velocidad de 6 de noviembre de 2012, accesible en: http://www.altavelocidad.org/ index.php/empresas/item/1413-francia-y-alemania-enrocan-sus-mastodontes-p\%C3\%BAblicos-ante-el-cuarto-paquete-ferroviario (consultado por última vez el 2.11.2017).

64 Accesible en: http://www.lavanguardia.com/economia/20160327/40694297434/competidoras-renfe-transporte-mercancias-tren.html (consultado por última vez el 2.11.2017).

65 Accesible en: http://www.arriva.co.uk/transport-leader/about-us/deutsche-bahn (consultado por última vez el 2.11..2017).

66 Accesible en http://www.sncf.com/fr/partenaires/keolis y en http://www.keolis.com/ en/business-activities/keolis-by-country/united-states.html, así como en http://www. keolisnorthamerica.com/ (consultados por última vez el 2.11.2017).

67 Keolis entró en el mercado de Estados Unidos en 2010. Virginia Railway Express eligió a su filial Keolis Rail para explotar la línea entre el estado de Virginia y Washington D. C. Accesible en: http://www.sncf.com/en/news/keolis-geodis-united-states (consultado por última vez el 2.11.2017).

68 Desde julio de 2014, accesible en: http://www.keolis.com/en/business-activities/keolis-by-country/united-states.html (consultado por última vez el 2.11.2017). 
en el ámbito del transporte de mercancías, especialmente dentro de la Unión Europea, Schenker (DB) ${ }^{69}$ y Geodis (SNCF) se han expandido a través de una política de compras compulsivas que casi siempre ha tenido como objetivo a filiales de operadores públicos privatizados. Además existen firmes sospechas de que estas operaciones han sido financiadas fundamentalmente con dinero de los contribuyentes alemanes y franceses ${ }^{70}$.

Por todo ello, la Comisión Europea, en su propuesta de medidas para el cuarto paquete ferroviario ${ }^{71}$, insiste en separar la gestión de las vías y la gestión de los trenes como elemento fundamental para eliminar los posibles conflictos de interés y ofrecer a las empresas un acceso a las vías no discriminatorio. Para ello propone: i) ampliar los requisitos de independencia a todas las funciones de los administradores de infraestructuras, ii) que la regla general sea la separación institucional entre gestores de red y operadores de transporte, iii) que no sea posible crear nuevas estructuras holding en el sector ferroviario y iv) que las estructuras holding integradas verticalmente ya existentes establezcan unas barreras infranqueables que garanticen la separación jurídica, financiera y operativa.

Asimismo, en la propuesta se reconoce expresamente que «es necesario garantizar la independencia jurídica, financiera y operativa para que haya igualdad de condiciones en la práctica y sea posible una competencia leal». Con esta afirmación, entendemos que la Comisión ha dado por fin un paso adelante muy significativo. Por una parte, admite la necesidad de una separación institucional («independencia jurídica»), en lugar de la mera separación contable que se ha venido exigiendo en este proceso de liberalización del sector ferroviario y que tantos problemas ha acarreado. Por otra parte, admite además la necesidad de una separación económica («independencia financiera y operativa») que, a nuestro modo de ver, resulta clave para garantizar el acceso no discriminatorio a las infraestructuras y la competencia en el sector ferroviario. De este modo, apelando al criterio económico para definir la separación de las actividades de gestión de las infraestructuras y de los servicios de transporte, se enlaza por fin con un principio básico de las normas de la competencia y, en particular, de las normas de control de las operaciones de concentración de empresas. Es el criterio que rige esta normativa pero que ha sido totalmente ignorado a lo largo de todo este proceso de liberalización del

69 DB Cargo Advantage es la mayor compañía de transporte de mercancías por ferrocarril de Europa. https://www.dbschenker.com/ho-de/produkte_services/schienengueterverkehr/db_cargo_vorteil_rail.html (consultado por última vez el 2.11.2017).

70 Es lo que afirma el Memorándum de la Comisión Europea, op. cit., nota 49, p. 4.

71 Ibid. p. 5. 
sector ferroviario, a pesar de que su principal problema sea precisamente el de la integración o concentración empresarial (infra 4 y IV).

\section{SEPARACIÓN ECONÓMICA Y SEPARACIÓN INSTITUCIONAL}

Con el fin de superar las ineficiencias advertidas en la separación entre la gestión de la red ferroviaria y los servicios de transporte, así como la persistencia de distorsiones en la competencia y en el acceso al mercado, el 14 de diciembre de 2016 se aprobó el pilar de mercado (pilar político o pilar de gobernanza) del cuarto paquete ferroviario. Los Estados tienen hasta el 25 de diciembre de 2018 para adaptar sus disposiciones internas a la Directiva (UE) 2016/2370, que modifica la Directiva 2012/34/UE en lo que atañe a la apertura del mercado de los servicios nacionales de transporte de viajeros por ferrocarril y a la gobernanza de las infraestructuras ferroviarias (art. 2) ${ }^{72}$. Desde un punto de vista jurídico-formal, la directiva sigue permitiendo las estructuras integradas verticalmente de tipo holding, pero introduce novedades importantes en la concepción de la gobernanza en el sentido que acabamos de indicar, al adoptar elementos y criterios económicos empleados en el ámbito del control comunitario de las concentraciones.

En primer lugar, debe señalarse que la Directiva (UE) 2016/2370 ordena algo totalmente novedoso como es la separación económica de las funciones esenciales de los gestores de infraestructuras (arts. 7.1.II, 7.4, 7.5 y 7 bis). Lo hace exigiendo que ninguna de las entidades jurídicas que formen parte de la empresa integrada verticalmente (es decir, ninguna de las que forme parte del holding ferroviario) tenga una «influencia decisiva» en las decisiones del gestor de infraestructuras en relación con dichas funciones (art.7.1.II y art.7.bis.2). Con ello, la directiva ha adoptado el mismo criterio que emplea el Reglamento comunitario de concentraciones (art. 3.2) para identificar la existencia de una concentración. Este reglamento no toma en consideración los aspectos jurídicos formales de las vinculaciones entre las empresas, sino sus efectos económicos. Ordena observar si una empresa pierde su independencia económica por el hecho de que otra haya adquirido el control sobre ella, aunque siga manteniendo su personalidad jurídica. Y prevé que una de las formas de adquirir el control sobre una empresa resulta precisamente de la posibilidad de ejercer una «influencia decisiva» sobre ella.

72 Aunque los arts. 10, 11, 11. bis y 13, relativos a las mejoras en los servicios de transporte de viajeros y las limitaciones del acceso a las infraestructuras ferroviarias, no serán de aplicación hasta enero de 2019 (art. 3, Directiva (UE) 2016/2370). 
En segundo lugar, la directiva establece, como regla general, la separación institucional del administrador de infraestructuras (art. 7.2). Exige que este se organice "como una entidad jurídicamente distinta de cualquier empresa" $y$, en el caso de empresas integradas verticalmente, como entidad distinta de cualquier otra entidad jurídica encuadrada en ellas. Así pues, como regla general, exige la separación jurídica formal del gestor de infraestructuras, reservando la separación económica únicamente para sus funciones esenciales. Ahora bien, esta exigencia va acompañada de una serie de prescripciones, a fin de garantizar la independencia del gestor de infraestructuras, que van más allá de una mera separación institucional jurídico-formal. Estas prescripciones prohíben que las mismas personas puedan tener al mismo tiempo puestos de decisión en la entidad administradora de las infraestructuras y en una empresa ferroviaria (art. 7.3) y también prohíben que el administrador y las empresas ferroviarias se concedan préstamos mutuamente (art. 7 quinquis). Todos estos matices nos hacen pensar casi en una separación económica plena del administrador de infraestructuras (no limitada a sus funciones esenciales) o cuando menos en una separación institucional que podríamos calificar de «enriquecida».

No obstante, como contrapunto de estas novedades substanciales en la gobernanza, queremos señalar que el artículo 7 quater de la Directiva (UE) 2016/2370 permite la externalización de las funciones del administrador de infraestructuras, siempre y cuando estas no sean llevadas a cabo por una empresa ferroviaria de forma directa o indirecta, salvo que se trate de trabajos en relación con el mantenimiento y la renovación de las infraestructuras ferroviarias. Asimismo, permite al administrador concluir acuerdos de colaboración con empresas ferroviarias siempre que no sean discriminatorios y se hagan en beneficio de los clientes ${ }^{73}$. Debe advertirse que estas posibilidades constituyen un margen de excepciones que pueden poner en entredicho las novedades mencionados en torno a la separación económica o independencia de las funciones del administrador de infraestructuras.

\section{IV. ¿̇INCONGRUENCIAS CON LAS NORMAS COMUNITARIAS DE LA COMPETENCIA?}

Analizado el proceso de liberalización del sector y de creación del espacio ferroviario único europeo, observamos que, pese a partir de la base de la con-

73 Nicolás NÄGELE HARCÍA DE FUENTES y Laura PELÁEZ GARCÍA, «El cuarto paquete ferroviario: pasos hacia la liberalización del sector», Actualidad jurídica Uría Menéndez, núm. 47, 2017, pp. 102-107. 
veniencia de separar las actividades ferroviarias de gestión de las infraestructuras y de prestación de los servicios de transporte, asistimos a la formación de unas estructuras empresariales de integración vertical cada vez más grandes y dominadoras. Si bien ya hemos puesto de manifiesto las ineficiencias observadas en las medidas adoptadas por las instituciones de la Unión Europea, llegados a este punto queremos mostrar además nuestro juicio acerca de su conformidad o idoneidad con los principios informadores y las normas comunitarias de la competencia, y más concretamente con los relativos al control de las estructuras en el mercado que, a nuestro modo de ver, han sido erróneamente ignorados hasta la reciente aprobación del cuarto paquete ferroviario.

\section{EL CONTROL DE LAS ESTRUCTURAS DE MERCADO}

Una de las principales preocupaciones de la política y del derecho de la competencia es el establecimiento de mecanismos que permitan a los poderes públicos controlar los procesos de formación de posiciones de dominio. Esto explica la relevancia de la normativa sobre el control de las concentraciones económicas que, en el caso de la Unión Europea, se centra en el Reglamento (CE) 139/2004 (Reglamento comunitario de concentraciones) ${ }^{74}$. Esta normativa tiene como fundamento la idea de que para asegurar el mantenimiento de una competencia efectiva en el mercado no basta con establecer un sistema dirigido a evitar y a controlar las colusiones o las situaciones de abuso de posición dominante. No basta con normas sobre el control de los comportamientos anticompetitivos (control anti-trust), sino que resultan necesarios otros instrumentos diseñados para actuar sobre los aspectos estructurales del mercado, es decir, normas de control de las estructuras (control de concentraciones).

74 El Reglamento (CE) 139/2004 del Consejo, de 20 de enero de 2004, sobre el control de las concentraciones de empresas (DO L 24, de 29 de enero de 2004, pp. 1-22), refunde las sucesivas modificaciones al Reglamento 4064/89 del Consejo, de 21 de diciembre de 1989, sobre el control de las operaciones de concentración entre empresas. Esta norma cuenta con un Reglamento de ejecución (UE) 1269/2013 de la Comisión de 5 de diciembre de 2013, por el que se modifica el Reglamento (CE) 802/2004, por el que se aplica el Reglamento (CE) 139/2004 del Consejo sobre el control de las concentraciones entre empresas (DO L 336, de 14 de diciembre de 2013, pp. 1-36). Se complementa con las «Directrices sobre la evaluación de las concentraciones horizontales» (DO C 31 de 5 de febrero de 2004 pp. 5-18) y con una serie de comunicaciones interpretativas de la Comisión Europea disponibles en la web de la Dirección General de la Competencia, sección concentraciones (Mergers), accesible en: http://ec.europa.eu/competition/mergers/legislation/legislation.html_(consultado por última vez el 2.11.2017). 
Huelga decir que las posiciones de dominio, tanto las ya existentes como la formación de nuevas posiciones, constituyen una preocupación constante en el proceso de liberalización del sector ferroviario. En Europa se partía de un modelo caracterizado por un único operador público que integraba verticalmente la gestión de la red ferroviaria y la explotación de los servicios de transporte, en un contexto de monopolio natural. Así que el objeto de la liberalización consiste, precisamente, en deshacer y controlar las posiciones de dominio de los operadores históricos verticalmente concentrados. Por ello, entendemos que los principios y normas sustantivas sobre control de las concentraciones deben constituir una referencia básica de este proceso, por lo que nos resulta inexplicable la ausencia que se ha producido durante todo este tiempo hasta la aprobación del cuarto paquete ferroviario.

Junto a las normas sustantivas, el sistema de control de las concentraciones cuenta con normas de procedimiento con el objeto de someter la realización de las operaciones de concentración a la obtención de una autorización administrativa previa (control ex ante). Su finalidad es la de conseguir que las estructuras del mercado sean lo más competitivas posible y evitar que, mediante concentraciones, las empresas alcancen o refuercen una posición de dominio en el mercado y puedan llegar a determinar su funcionamiento, por ejemplo, imponiendo subidas de precios o condiciones de mercado no equitativas. De este modo, esta regulación desempeña una función preventiva y ordenadora. En lugar de prohibir las concentraciones de empresas, se centra en impedir que como consecuencia de ellas se produzcan efectos lesivos para la competencia y el buen funcionamiento del mercado. Se trata de un control preventivo, ya que si el control se realizara después de haberse llevado a cabo la concentración (control ex post), la solución de deshacerla resultaría costosa y además ineficaz para volver al estado anterior a la ejecución ${ }^{75}$.

Obviamente, el sistema comunitario de control de las concentraciones se aplica también al sector ferroviario, pero tiene aquí un alcance limitado. Este control ex ante se aplica con carácter general a todos los proyectos de concentración de dimensión comunitaria sometidos a la obligación de notificación previa a la Comisión Europea, según el Reglamento comunitario de concentraciones (art. 4$)^{76}$. En el sector ferroviario, las operaciones notificadas

75 Ricardo ALONSO SOTO, «Capítulo 14. Derecho de la competencia III. El control de las concentraciones de empresas», en Rodrigo URÍA y Aurelio MENÉNDEZ (dirs.), Curso de Derecho Mercantil I, 2a ed., Thomson Civitas, Madrid, 2006, pp. 335-371.

76 Véanse las decisiones de la Comisión Europea autorizando las operaciones de concentración: Decisión de 17 de junio 2010, as. COMP/M.5655 SNCF/LCR/Eurostar; 
generalmente han consistido en la creación de nuevos operadores mediante empresas en participación de plenas funciones (art. 3.4), en la terminología del Reglamento comunitario de concentraciones. No se han llevado a cabo fusiones o concentraciones entre operadores históricos (como DB, SNCF o RENFE) $)^{77}$.

Pero, como se ha explicado, este sistema no contempla la posibilidad de un control ex post. Por lo tanto, no sirve para atacar los problemas de dominio de las concentraciones ya existentes, los problemas de unos operadores ferroviarios con estructuras empresariales verticalmente integradas a modo de holding que se crearon con anterioridad a la apertura a la competencia del tráfico de mercancías (en enero de 2007) y del tráfico internacional de viajeros (en enero de 2010). Ahí es, precisamente, donde queremos llegar, a denunciar el hecho de que, desde su inicio, en el proceso de liberalización del sector ferroviario no se hayan empleado unas medidas eficientes para evitar que esos operadores hayan incrementado su peso en el mercado.

\section{CRITERIOS JURÍDICOS VS. CRITERIOS ECONÓMICOS}

El ámbito de aplicación objetivo de las normas que conforma este sistema son las concentraciones de empresas, cuya definición se contiene en el art. 3 del Reglamento comunitario de concentraciones. No obstante, conviene realizar algunas precisiones para situar esta definición en su contexto. Conviene recordar que la noción de concentración varía en función del enfoque utilizado $^{78}$, que generalmente es el jurídico o el económico, y que estos dos enfoques no son complementarios, sino que, en cierto modo, se contraponen.

Empleando criterios jurídicos, la existencia de una concentración se constata por la presencia de determinadas figuras o el cumplimiento de procedimientos previstos por el ordenamiento jurídico, considerados aptos para llevar a cabo una integración económica. La fusión, la adquisición de acciones o participaciones de sociedades, la adquisición o intercambio de activos, los contratos de cesión de la gestión de una empresa, etc., son figuras que dan lugar a concentración. El criterio jurídico es un criterio formal, consiste en

Decisión de 23 de julio de 2012, as. COMP/M.6596 SNCF-P/Groupe Keolis; Decisión de 27 de enero de 2016, as. Arriva/Rail North/Northern Franchise; Decisión de 5 de mayo de 2017, as. COMP/M.8441 Firstgroup/MTR Corporation/Western Rail Franchise.

77 José AYLLÓN, «Alianzas y fusiones transfronterizas en el transporte ferroviario de pasajeros en la Unión Europea», Revista de Derecho de la Unión Europea, núm. 25, 2013, pp. 221-236.

78 ALONSO, op. cit., nota 75, p. 336. 
verificar la presencia de determinadas formalidades jurídicas. Por tanto, ofrece la ventaja de proporcionar un alto grado de seguridad jurídica. Pero tiene el inconveniente de que no toma en consideración los efectos económicos que esas operaciones tipificadas legalmente y cualesquiera otras pueden tener en el mercado.

El criterio económico, en cambio, se fija en los resultados (económicos) alcanzados con el proceso desarrollado, sea cual sea, prescindiendo totalmente de las formalidades jurídicas. Así, el elemento determinante para constatar la existencia de concentración es la pérdida de independencia económica que se produce a través de la adquisición de control de una o varias empresas por parte de otra u otras. Lo relevante en la concentración o integración económica es observar si las empresas se encuentran bajo una misma unidad de dirección, de modo que su política empresarial sea establecida por la empresa que haya asumido el control ${ }^{79}$. Este es un criterio más flexible y más eficaz desde el punto de vista de defensa de la competencia, que da lugar a un concepto bastante más amplio de concentración, aunque no ofrezca un nivel de seguridad jurídica tan alto como el criterio jurídico.

Por las razones expuestas, el criterio adoptado por las normas de la competencia y por el Reglamento comunitario de concentraciones es el criterio económico. Se sacrifica un cierto grado de seguridad jurídica en favor de la eficiencia, necesaria para alcanzar los fines de establecer un régimen que garantice que la competencia no sea distorsionada en el mercado interior (TFUE art. 3.1.g ${ }^{80}$, algo que no podría alcanzarse aplicando exclusivamente criterios jurídicos formales.

Sin embargo, en el ámbito ferroviario, las directivas comunitarias que se han dictado para la liberalización del sector sistemáticamente han seguido criterios jurídicos y no económicos. Tenían por objeto acometer la reestructuración de los operadores ferroviarios históricos con posiciones de monopolio en los mercados nacionales, sobre la base de la separación entre los gestores de infraestructuras y los operadores de servicios de transporte. Para ello, las sucesivas directivas han exigido el cumplimiento de determinados requisitos jurídico-formales, como el del estatus jurídico de las empresas ferroviarias independientes del Estado, la contabilidad separada de las actividades de gestión de las infraestructuras y de los servicios de transporte (Directiva 91/440/CE),

\footnotetext{
79 Véase la Comunicación de la Comisión Europea sobre el concepto de concentración, de 2 de marzo de 1998, que ofrece una interpretación de lo que debe entenderse por adquisición de control y que establece la distinción entre control exclusivo y control conjunto.

80 Reglamento comunitario de concentraciones, considerandos n. 2 y 3 .
} 
la separación jurídica de las funciones esenciales de los administradores de infraestructuras (Directiva 2001/12/CE) o la separación, al menos orgánica, de los gestores de infraestructuras cuando las actividades de infraestructuras y de transporte se desarrollen por un misma empresa (Directiva 2012/34/UE) ${ }^{81}$.

Pero estas directivas no han contemplado la valoración de elementos y efectos económicos de las estructuras integradas por las empresas ferroviarias. De este modo han permitido la existencia y formación de estructuras empresariales que, en virtud del Reglamento comunitario de concentraciones (art. 3) serían calificadas como tales, como empresas con actividades integradas, no separadas. Es decir, han permitido la existencia de unas estructuras que son, precisamente, contrarias a su objetivo de reestructurar el mercado y de separar la gestión de las infraestructuras y los servicios de transporte ${ }^{82}$.

\section{VALORACIÓN Y PERSPECTIVAS DE FUTURO}

A modo de valoración, queremos señalar que durante veinticinco años (de 1991 a 2016) las directivas destinadas a establecer un mercado ferroviario en competencia no han prestado atención a los efectos económicos de las relaciones de mercado entre los gestores de red y los operadores de transporte, desatendiendo así los principios generales que rigen las normas comunitarias de la competencia. A ello hay que añadir que, en una apreciación global de los resultados alcanzados por ellas, nuestra valoración sobre la apertura a la competencia no es positiva y que el avance debe calificarse de lento o muy lento.

Entre las debilidades del proceso de apertura al mercado del sector ferroviario se suele llamar la atención sobre la mala experiencia en la transposición de las directivas por parte de los Estados miembros ${ }^{83}$, especialmente de las directivas del primer paquete ${ }^{84}$. En casi todos los casos se han detectado irregularidades de mayor o menor calado ${ }^{85}$, ya sea por el retraso en la trans-

81 Estas exigencias se acompañan de otras relativas a la seguridad, interoperabilidad, liberalización del transporte de mercancías por ferrocarril, tarificación, creación de una Agencia Ferroviaria Europea, etc.

82 En este sentido, ordenando la separación económica de las empresas que integran el holding, véase Monopolкommission, op. cit., nota 53, p. 19 ss.

83 Las referencias a los Estados miembros deben entenderse sin incluir a Chipre y Malta, que no disponen de red ferroviaria.

84 Miren Igone ALTZELAI ULIONDO, «Hacia un espacio ferroviario europeo único», Revista de Derecho del Transporte, núm. 10, 2012, pp. 79-106.

85 Véase el informe de la Comisión al Parlamento Europeo y al Consejo «Segundo Informe sobre el seguimiento de la evolución del mercado ferroviario», COM(2009) 676 final, de 18.9.2009, n. 11 . 
posición, por no iniciar su aplicación o por hacerlo de forma incompleta. Las principales irregularidades son las referidas a: la falta de independencia de los administradores de infraestructuras respecto de los operadores ferroviarios, la aplicación insuficiente de las normas de la directiva sobre la determinación de las tarifas de acceso a las vías o los cánones por utilización de infraestructuras, la ausencia de un régimen de prestaciones para mejorar el rendimiento de la red ferroviaria, la falta de incentivos de los citados administradores para reducir los costes y los cánones y la carencia de los organismos reguladores independientes de poderes para resolver los problemas de competencia en cada uno de los mercados nacionales. Ciertamente, esta situación llevó a la Comisión Europea a iniciar en 2008 procedimientos de infracción de normativa comunitaria contra veinticuatro de los veinticinco Estados implicados. Tras enviar cartas de apercibimiento a todos ellos, solo tres introdujeron modificaciones en sus legislaciones nacionales. En 2009 la Comisión Europea envió a veintiún miembros dictámenes motivados en relación con las infracciones pendientes, y finalmente, en 2010, decidió interponer recursos por incumplimiento contra trece países (Alemania ${ }^{86}$, Austria, República Checa, Eslovenia, España ${ }^{87}$, Francia, Grecia, Hungría, Irlanda, Italia, Luxemburgo, Polonia y Portugal).

No obstante, en lugar de centrarnos en estas irregularidades de los Estados, con este trabajo hemos querido poner de manifiesto las debilidades de las propias directivas, o mejor dicho, sus incongruencias con los principios y criterios que rigen las normas comunitarias de la competencia y las consecuencias que ello ha acarreado para la creación de un espacio ferroviario único europeo. El hecho de que las directivas hayan limitado su acción a un control jurídico formal sobre los agentes del sector ferroviario, en lugar de ejercer sobre ellos un control basado en criterios económicos propio de las normas de la competencia, ha propiciado el mantenimiento de unas estructuras que el proceso liberalizador tenía por objeto deshacer.

86 En las sentencias del Tribunal de Justicia Comisión/Alemania, C-556/10, EU:C: 2013:116 y C-482/14, EU:C:2017:499, el Tribunal ha rechazado los recursos de la Comisión por no estimar suficientemente probada la falta de independencia exigida por las directivas ferroviarias.

87 La sentencia del Tribunal de Justicia Comisión/España, C-483/10, EU:C:2013:114, condenó a este por incumplir las normas en materia de liberalización del transporte ferroviario relativas a los sistemas de tarificación de las infraestructuras. Al respecto, véase José María COLLADO GONZÁLEZ, «Divergencias entre la legislación española sobre transporte ferroviario y la regulación comunitaria. El procedimiento de infracción incoado al Reino de España», Revista de Derecho de la UE, núm. 25, 2013, pp. 169-190. 
Queremos ser optimistas ante la nueva etapa que se inicia con el cuarto paquete ferroviario, gracias a las novedades introducidas por la Directiva (UE) 2016/2370, más en consonancia con los principios que rigen el sistema comunitario de la competencia, en especial con las normas sobre el control de concentraciones. La directiva ordena la separación económica de las funciones esenciales de los administradores de infraestructuras y, en todo caso, su separación institucional. Exige que se organicen como entidades jurídicamente distintas de cualquier otra empresa. Además, esta es una separación institucional que calificamos de «enriquecida», puesto que va acompañada de una serie de prescripciones destinadas a garantizar la independencia de los administradores, más allá de la mera separación jurídica formal.

Así pues, el balance es bastante positivo, aunque no totalmente, puesto que la Directiva (UE) 2016/2370 no llega a ordenar la plena separación económica de los administradores de infraestructuras, sino que la limita a sus funciones esenciales de asignación de surcos y de tarificación. Además, debe recordarse que la directiva permite a los administradores de infraestructuras externalizar sus funciones y concluir acuerdos de colaboración con empresas ferroviarias bajo determinadas condiciones, siempre que no sean discriminatorios y se hagan en beneficio de los clientes. Como ya hemos puesto de relieve (supra III.4), estas posibilidades podrían hacer frenar, incluso peligrar, los avances introducidos por la directiva en torno a la separación económica $o$ independencia de las funciones esenciales de los administradores de infraestructuras.

\section{CONCLUSIONES}

Del estudio llevado a cabo sobre la creación del espacio ferroviario único europeo y las normas que en este proceso de liberalización del sector regulan las relaciones entre los gestores de las infraestructuras ferroviarias y los operadores de los servicios de transporte, extraemos las siguientes conclusiones:

1. En el sector ferroviario, los administradores de las infraestructuras y las empresas explotadoras de los servicios de transporte son operadores situados en diferentes estadios de una misma cadena de valor, ofertan servicios complementarios entre sí, por lo que mantienen una relación de mercado vertical. Desde el punto de vista del derecho de la competencia, esta es una relación peligrosa que entraña riesgos para el correcto funcionamiento del mercado, siendo este precisamente el objetivo que se pretende conseguir con la creación de un espacio ferroviario único europeo. 
Entraña riesgos de discriminación en el acceso de los operadores al mercado ferroviario, riesgos de subvenciones cruzadas y riesgos propios de las relaciones verticales como es la formación de posiciones de dominio. A este respecto, conlleva, por un lado, el riesgo de un déficit de competencia en uno o varios niveles del comercio, algo que no es lo deseado cuando se está tratando de liberalizar un sector económico y crear un espacio en competencia. Por otro lado, también genera el consiguiente riesgo de abuso de posición dominante, algo que, obviamente, está prohibido por las normas de defensa de la competencia y que, en cualquier caso, es preferible prevenir.

2. Con el fin de alcanzar un mercado ferroviario en competencia minimizando estos riesgos, la Unión Europea ha defendido la separación de la gestión de las infraestructuras ferroviarias y la prestación de los servicios de transporte, como pilar fundamental del proceso de liberalización del sector, desde sus inicios. Esta es una premisa totalmente lógica desde el punto de vista concurrencial, pero la política practicada no ha sido acorde con los principios del sistema comunitario de defensa de la competencia.

3. Como resultado de esta política, los Estados miembros de la Unión Europea iniciaron una etapa dedicada a segregar los administradores de infraestructuras y los operadores de transportes históricamente integrados de forma vertical. Sin embargo, ello acarreó numerosos problemas y también se plantearon fuertes resistencias por parte de algunos Estados que optaron por morfologías diversas de tipo holding, compatibles con las exigencias jurídicas de las directivas ferroviarias.

4. Con ello, esta política no ha seguido de manera fiel y ortodoxa los dictados del sistema comunitario de defensa de la competencia, sino que ha rebajado notablemente los rigores impuestos por sus normas. El resultado es que ha proporcionado cobertura a los estados que se han aferrado a las estructuras de holding, cuyos operadores en los últimos años se han beneficiado ampliamente de una situación de ventaja competitiva. Gracias al poder económico que les confería su estructura integrada han podido penetrar en mercados de países en los que el operador histórico integrado verticalmente había sido dividido o había desaparecido. De este modo, la política de la Unión Europea ha permitido la creación y consolidación de importantes posiciones de dominio ab initio en el espacio ferroviario único europeo.

5. La etapa que se abre con el cuarto paquete ferroviario es algo más esperanzadora porque contempla la separación económica de las funciones esenciales de los administradores de infraestructuras. Constituye un avance significativo, pero sigue sin ordenar su separación económica to- 
tal y prevé además un margen de excepciones cuya aplicación habrá que vigilar. Esto nos lleva a concluir que probablemente sean necesarias nuevas medidas para hacer cumplir fehacientemente estas previsiones, unas medidas que, en la línea de las normas de defensa de la competencia, pongan el acento en la valoración de los elementos y efectos económicos de las estructuras integradas por las empresas ferroviarias y que dispongan las consecuencias jurídicas oportunas para superar y tratar de evitar las distorsiones generadas por ellas. La nueva etapa exige un cambio conceptual, esencial para gestionar este proceso de liberalización, por lo que no se descarta un quinto paquete ferroviario para poder cumplir los objetivos de creación de un espacio ferroviario europeo único en competencia. 